\title{
La escritura de los efectos de la pérdida de la memoria en
} "H.", de Carlito Azevedo

Writing on the effects of memory loss in «H.», by Carlito Azevedo

\section{Renata Cristina Pereira Raulino ${ }^{1}$}

Faculdade de Filosofia, Letras e Ciências Humanas de la Universidade de São Paulo (Brasil) renata.raulino@usp.br

ORCID 0000-0002-5229-5061

Citar como: Pereira, R. (2019). La escritura de los efectos de la pérdida de la memoria en «H.» de Carlito Azevedo. Desde el Sur, 11 (2), pp. 343-350.

\section{RESUMEN}

En nuestro momento actual, en el cual el ejercicio de la memoria es tan fundamental, surgen producciones literarias que reflexionan sobre la pérdida de la memoria, como la que es causada por el Alzheimer. En este ensayo, propongo el análisis de los principales procedimientos literarios que el poeta brasileño Carlito Azevedo usa para expresar los efectos del Alzheimer de su madre en el poema «H.», publicado en el poemario Monodrama (2009). Por lo tanto, el poeta-hijo se concentra particularmente en la ausencia y, por medio de su escritura, evidencia los vacíos de la memoria de su madre.

\section{PALABRAS CLAVE}

Memoria, olvido, Alzheimer, Carlito Azevedo, «H.»

\section{ABSTRACT}

In our own time, in which the exercise of memory is so fundamental, literary works have emerged which reflect upon the loss of memory, including the memory loss caused by Alzheimer's disease. In this essay, we offer an analysis of the main literary devices employed by the

1 Maestra por el Programa de Pós-graduação em Língua Espanhola e Literaturas Espanhola e Hispano-Americana de la Faculdade de Filosofia, Letras e Ciências Humanas de la Universidade de São Paulo (Brasil). Doctoranda del mismo Programa, con la investigación «Formas do esquecimento: escritura do Alzheimer na literatura latino-americana contemporânea». Becaria de Coordenação de Aperfeiçoamento de Pessoal de Nível Superior (CAPES, Brasil). 
Brazilian poet Carlito Azevedo in order to describe the effects of Alzheimer's disease upon his mother, in the poem «H.», published in the collection Monodrama (2009). Here, the poet-son focuses particularly upon absence and, through his writing, he evokes the gaps in his mother's memory.

\section{KEYWORDS}

Memory, forgetting, Alzheimer's disease, Carlito Azevedo, $\mathrm{H}$

Este breve ensayo está organizado en tres partes. Primero, trataré del ejercicio intenso de la memoria y, simultáneamente, el miedo al olvido en manifestaciones artísticas actuales.

Enseguida, presentaré un análisis de los modos en que el poeta brasileño Carlito Azevedo expresa la enfermedad de Alzheimer de su madre en la estructura del poema «H.», publicado en el poemario Monodrama (2009).

Para concluir, reflexionaré sobre la escritura del poema como un modo de expresar la continuación de una relación madre e hijo, a pesar de la enfermedad, a pesar de la muerte.

En el libro En busca del futuro perdido: cultura y memoria en tiempos de globalización, Andreas Huyssen (2002) argumenta que, si en el inicio del siglo XX la cultura occidental ponía su atención en las transformaciones y tecnologías que la humanidad usaba para construir una visión futurista de las sociedades, en la última década del siglo XX y en el inicio del siglo XXI el deseo de imaginar un futuro se retira para dar espacio a una atención volcada al pasado. Por eso, han explotado manifestaciones artístico-culturales preocupadas en figurar y reflexionar acerca de los límites y las posibilidades de la memoria. Simultánea y proporcionalmente, ha aumentado el pánico generalizado por el olvido.

Tal vez semejante temor por el olvido esté relacionado con el miedo al Alzheimer, una enfermedad neurodegenerativa que puede llevar a un ser humano a perder irreversiblemente la memoria, el lenguaje, la noción de tiempo, la dirección, la autopercepción y el autocontrol. Además, es incurable. En la introducción a Popularizing Dementia. Public Expressions and Representations of Forgetfulness, Aagje Swinenn y Mark Schweda (2015) llaman la atención a la existencia de declaraciones y campañas públicas que postulan que esa enfermedad es vista como la plaga del siglo XXI. 
Resaltan que nuestra sociedad valora el desempeño cognitivo y la autonomía individuales, confiando a los individuos la responsabilidad sobre su propia salud. Por lo tanto, el enfermo siente la enfermedad como una tragedia individual, como un desafío para mantener relacionamientos, y simultáneamente como un gran problema de la sociedad como un todo. De esta manera, el Alzheimer no se restringe al discurso médico, sino que se integra a la imaginación pública y se manifiesta en diversas obras artísticas de, por ejemplo, el cine, las artes plásticas y la literatura.

En esta perspectiva, en mi proyecto de doctorado, analizo cómo autores expresan los efectos de la pérdida de memoria en cinco textos literarios latinoamericanos, en los cuales uno de los personajes principales está con Alzheimer. En este ensayo, haré un breve e inicial análisis de los principales procedimientos literarios que el poeta brasileño Carlito Azevedo usa para expresar los efectos del Alzheimer de su madre en el poema «H.» publicado en Monodrama (2009) ${ }^{2}$.

En un momento en que la memoria es tan importante, la escritura parece ser una especie de remedio que nos ayuda a recordar. Al mismo tiempo, estoy de acuerdo con Harald Weinrich (2001) en Lete, cuando argumenta que la escritura también es aliada del olvido si pensamos solo en nuestra memoria natural, porque la revolución escritural de las sociedades occidentales debilitó nuestra capacidad de recordar. Por eso, muchas veces, escribir se relaciona con una condición de la memoria que expone sus limitaciones: lo que alguien escribe en el papel frecuentemente se saca de la memoria natural y, por consiguiente, se olvida.

De esa manera, el poeta figura a la madre con Alzheimer como animal obliviscens, un ser que se olvida. La preocupación con relatar la pérdida de la memoria ajena demuestra una conciencia de que la lucha contra esa enfermedad fue una batalla inevitablemente perdida: en vez de solo mostrar la presencia de la memoria en ruina, Carlito Azevedo ${ }^{3}$ se enfoca en lo que falta y evidencia el olvido, no solamente para seleccionar recuerdos, sino para exhibir los vacíos de la memoria.

2 Los otros cuatro textos que componen el corpus de mi investigación de doctorado son Desarticulaciones (2010), de Sylvia Molloy; El eco de mi madre (2010), de Tamara Kamenszain; Diário da queda (2011), de Michel Laub; y Mar azul (2012), de Paloma Vidal.

3 Carlito Azevedo nació en Río de Janeiro en 1961. Es editor de la revista Inimigo Rumor, traductor, crítico y poeta. Publicó los poemarios Collapsus linguae (1991), As banhistas (1993), Sob a noite física (1996) y Versos de circunstância, en 2001, año en que también reunió la mayoría de sus poemas en la antología Sublunar (1991-2001). Monodrama (2009) y Livro das Postagens (2016) son sus libros más recientes. 
Al relatar la historia de la enfermedad y muerte maternas como parte fundamental de su propia narrativa de vida, Azevedo también lucha con el olvido en el acto de escribir. Escribe sus limitaciones y dificultades, que parecen estar vinculadas al contacto con la enferma con disturbios de memoria y de lenguaje. De esa manera, no parece solamente usar la memoria contra el olvido, sino que principalmente explicita sus mecanismos en la escritura, tanto en su forma como en su contenido. Por lo tanto, el poeta lleva al extremo la siguiente reflexión que Sergio Chejfec (2015) hace en «Lengua simple, nombre»: «escribir no es recordar; sino, al contrario, delimitar lo que es imposible de recuperar» (Chejfec, 2015, párr. 22).

En el poema que estoy analizando, el escritor llama la alternancia entre presente y pasado de «assustadora simultaneidade», pero la voz poética no confunde temporalidades, efecto recurrente para quien es enfermo de Alzheimer. Por eso, en una lectura más detenida del poema, me llamó la atención la escasez de referencias a un futuro y de un futuro más allá de la muerte, vacío que la voz imaginada de la madre lamenta en los últimos versos en discurso directo:

- Comparada com a larga eternidade de nada sentir, nada provar, nada tocar, ver e ouvir que nos espera, a morte no sono, como dizem que coube a Chaplin, [...] nesse louco planeta que agora, para você, gira também sem mim [Comparada con la larga eternidad de nada sentir, nada probar, nada tocar, ver y oír que nos espera, la muerte en el sueño, como dicen que le correspondió a Chaplin, [...]

en este loco planeta que ahora, para ti, gira también sin $\mathrm{mi}^{4}$ ] (Azevedo, 2009, p. 152).

A lo largo del poema, hay un escaso uso de verbos conjugados en el futuro. Cuando estos aparecen, no están relacionados con acciones concretas, sino a sensaciones, previsiones y deseos:

Passeio agora pela mesma casa de minha infância, adolescência e vida adulta, consolado pela ideia do descanso que ela terá de agora em diante [...]

4 Todas las traducciones de los fragmentos del poema para la lengua española, entre corchetes, son mías. 
[Paseo ahora por la misma casa de mi infancia, adolescencia y vida adulta, consolado por la idea del descanso que ella tendrá de ahora en adelante] (Azevedo, 2009, p. 138).

Sinto que se conseguir escrever agora o que se passa comigo estarei salvo, repito isso a mim mesmo algumas vezes [...]

[Siento que si conseguir escribir ahora qué pasa conmigo estaré salvado, repito eso a mi mismo algunas veces] (Azevedo, 2009, p. 139).

El futuro es una de las dimensiones temporales que el enfermo de Alzheimer puede perder, porque la incapacidad de producir nuevos recuerdos es normalmente uno de sus primeros síntomas, de acuerdo con Daniela Feriani (2017) en Entre sopros e assombros: estética e experiência da doença de Alzheimer.

La escritura de la enfermedad materna también parece afectar la estructura rigurosa del poema: «H.» se divide en cuatro partes con cuatro estrofas cada una. Esta división simétrica se desestabiliza, por lo que Lu Menezes, en un comentario en la antología de poemas de Carlito titulada Sublunar (2001), habla de impulsos asimétricos y afectivos tan potentes que quiebran el eslabón entre el rigor y la simetría, entre el rigor y la asepsia emocional.

Los versos salen de una métrica definida y los relatos rompen con un orden cronológico $u$ otra coherencia formal, porque se trata de un poema en prosa en el cual el corte del verso está a punto de desaparecer. En «H.», la dualidad entre la rigidez estructural y la materia afectiva irreductible crea una textualización de la corrosión de la memoria por el Alzheimer, en que solo restos de recuerdos sobreviven.

A su vez, el uso de iniciales de nombres propios es una manera de escribir la pérdida de la memoria del lenguaje y, al mismo tiempo, la incapacidad de reconocer plenamente a las personas a quienes los nombres se refieren:

A. e B. necessitam ouvir música para escrever, já M. e W. requerem nessa hora todo o silêncio possível [...] [A. y B. necesitan oír música para escribir, ya M. y W. requieren en esa hora todo el silencio posible] (Azevedo, 2009, p. 145). 
Además, la letra $h$ no tiene sonido sola en portugués, es una letra muda.

Por fin, otra forma importante de incorporar la enfermedad de Alzheimer en la escritura del poema reside en la creación de imágenes. Algunas de estas indican pensamientos desconectados y sin límites entre la racionalidad y la irracionalidad; por ejemplo, las que remiten a situaciones antitéticas, como un «banquete fúnebre» (Azevedo, 2009, p. 150) en el restaurante de comida rápida árabe Habib's y las que muestran una percepción atenta a lo escatológico del cotidiano: «recheio de carne morta» (Azevedo, 2009, p. 151); «merda» (Azevedo, 2009, p. 138).

De acuerdo con Pavis (2011) en su Dicionário do teatro, la forma teatral monodrama es un tipo de representación dramática en la cual el mundo que rodea al personaje aparece como el personaje lo percibe. A través de este ambiente, el público tiene que volverse cómplice del protagonista. En el libro de poemas Monodrama, la centralidad y la identidad de ese sujeto se quiebran en varias otras perspectivas y crean una profusión desconectada de imágenes. Así, en «H.», el sujeto-poeta-hijo trata de expresar los síntomas de la madre con Alzheimer en la propia estructura del poema.

Daniela Feriani (2017) afirma que un discurso muy común sobre esta enfermedad construye la figura del enfermo como alguien que falla en reconocer a las personas afectivamente más cercanas. En este caso, la «tragedia» de esa condición es típicamente percibida cuando se violan las convenciones sociales de intercambios amorosos. Sin embargo, los eventos que podrían provocar tal aislamiento y una desconexión con quién o con qué está alrededor de la madre enferma no pasan, a pesar del riesgo. El poeta no olvida quién está olvidándose. La comunicación entre madre e hijo falla, pero sobrevive a través de la escritura. Ella es la destinataria y motor de la escritura desde el título mismo.

De esta manera, al explorar las fallas y vulnerabilidades de una memoria en descomposición, el escritor-poeta-hijo escribe un poema poroso y desarticulado con una temporalidad presente que se desvía de la reconstrucción de un pasado o de un futuro para concentrarse en la reflexión de su pérdida inevitable, de la caída en el olvido. Por lo tanto, «H.» es una escritura del duelo. Carlito Azevedo materializa los efectos de la pérdida de la memoria materna y, enseguida, de la muerte de la madre en su propia vida. Esta doble pérdida continúa siendo compartida a través del acto de escribir y de leer el poema. Azevedo no escribe acerca del otro, sino que lo inscribe, lo incorpora en descomposición, en la enfermedad y en la muerte. 


\section{Contribuciones}

Renata Cristina Pereira Raulino ha participado en la concepción del artículo, la recolección de datos, su redacción y aprobación de la versión final.

\section{Fuentes de financiamiento}

Coordenação de Aperfeiçoamento de Pessoal de Nível Superior (CAPES, Brasil).

\section{Conflictos de intereses}

La autora declara no tener conflictos de interés. 


\section{REFERENCIAS BIBLIOGRÁFICAS}

Azevedo, C. (1993). As banhistas. Río de Janeiro: Imago.

Azevedo, C. (1996). Sob a noite física. Río de Janeiro: 7Letras.

Azevedo, C. (2001). Sublunar (1991-2001). Río de Janeiro: 7Letras.

Azevedo, C. (2009). Collapsus linguae. Río de Janeiro: 7Letras.

Azevedo, C. (2016). O livro das postagens. Río de Janeiro: 7Letras.

Azevedo, C. (2009). Monodrama. Río de Janeiro: 7Letras.

Chejfec, S. (2015). Lengua simple, nombre. Asymptote. Recuperado de https://www.asymptotejournal.com/nonfiction/sergio-chejfec-simplelanguage-name/spanish/

Feriani, D. (2017). Entre sopros e assombros. Estética e experiência na doença de Alzheimer (tesis doctoral). Instituto de Filosofia e Ciências Humanas, Universidade Estadual de Campinas, São Paulo. Recuperado de http://repositorio.unicamp.br/handle/REPOSIP/324984

Huyssen, A. (2002). En busca del futuro perdido. Buenos Aires: Fondo de Cultura Económica.

Kamenszain, T. (2010). El eco de mi madre. Buenos Aires: Bajo La Luna.

Laub, M. (2011). Diário da queda. São Paulo: Companhia das Letras.

Molloy, S. (2010). Desarticulaciones. Buenos Aires: Eterna Cadencia.

Pavis, P. (2011). Dicionário de teatro. São Paulo: Perspectiva.

Swinnen, A. y Schweda, M. (Eds.) (2015). Popularizing Dementia. Bielefeld: Transcript Verlag.

Vidal, P. (2012). Mar azul. Río de Janeiro: Rocco.

Weinrich, H. (2001). Lete. Río de Janeiro: Civilização Brasileira. 